\title{
Loudspeaker Noise Disturbance Control using Optimal and Robust Controllers
}

\author{
Mustefa Jibril $^{1}$, Messay Tadese ${ }^{2}$, Fiseha Bogale ${ }^{3}$ \\ ${ }^{1}$ Msc, School of Electrical \& Computer Engineering, Dire Dawa Institute of Technology, Dire Dawa, \\ Ethiopia \\ ${ }^{2}$ Msc, School of Electrical \& Computer Engineering, Dire Dawa Institute of Technology, Dire Dawa, \\ Ethiopia \\ ${ }^{3}$ Msc, Department of Mechanical Engineering, Kombolcha Institute of Technology, Wollo, Ethiopia \\ mustefa.jibril@ddu.edu.et
}

\begin{abstract}
Noise reduction is the major issue in the loudspeaker for the application of the musical instruments and related areas. In this paper, a noise disturbance control of a loudspeaker with optimal and robust controllers has been done successfully. The noise of the loudspeaker has been analyzed by simply track a reference cone displacement with the actual cone displacement. Static output feedback and $\mathrm{H}$ coptimal loop shaping controllers have been used to compare the actual and reference cone displacements by using a sine wave and random cone displacement signals and a promising results have been analyzed.
\end{abstract}

Keywords: Loudspeaker, Cone, Static output feedback, H $\infty$ optimal loop shaping

\section{Introduction}

A loudspeaker is an electroacoustic transducer in which converts an electrical signal into a corresponding sound. The bulk widely used type of loudspeaker is the dynamic speaker. The sound source must be amplified or strengthened with an audio amplifier before the signal is fed to the loudspeaker. The dynamic loudspeaker operates on the same basic doctrine as a dynamic microphone, but in reverse, to get sound from an electrical signal. When an alternating current electrical signal is applied to its voice coil, a coil of wire suspended in a circular gap between the poles of a permanent magnet, the coil is forced to event rapidly back and forth due to Faraday's law of induction, which causes the cone attached to the coil to action back and forth, pushing on the air to create sound waves. Besides this common method, there are many option technologies that can be used to convert an electrical signal into sound. Speakers are typically contained in a speaker lot or speaker cabinet which is often a rectangular square box made of several forms of wood, or sometimes plastic. The enclosure's materials and design pleasure an important role in the importance of the sound. Smaller loudspeakers are found in scheme such as radios, televisions, portable audio players, computers, and electronic musical instruments. Larger loudspeaker procedure is used for music, sound reinforcement in theatres and concert halls, and in public address systems.

\section{Mathematical Modelling}

A voltage is applied across the terminals of the speaker and the "cone" moves in and out position causing wave pressure as sound. To understand the mission of a speaker, consider the diagram 
shown in Figure 1. The speaker is composed of a cone with mass (M), that moves in the $\mathrm{x}$ direction. The cone is designed with a spring $(\mathrm{K})$ to revenue it to its equilibrium position, and a friction coefficient (B). Attached to the cone, and within the magnetic field is a coil of string with radius "a." The coil consists of " $n$ " turns and it moves along with the cone. The wire has opposition resistance $(\mathrm{R})$ and inductor $(\mathrm{L})$.

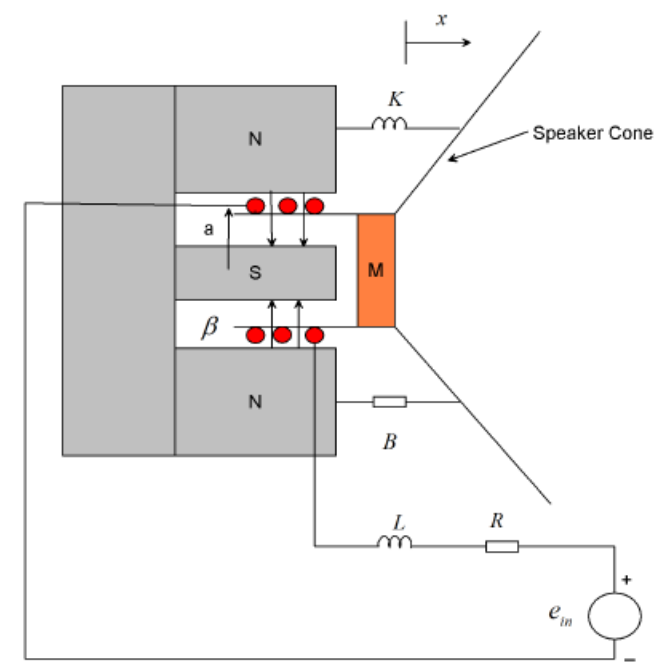

Figure 1 Design of a loudspeaker

As a current pass through the coil, the generated force moves the cone. A back emf is generated in the coil. Since the velocity (v) is positive entrance out of the screen and the magnetic field $(\beta)$ is towards the center of the coil, the right hand rule shows that the polarity of the induced voltage is in the positive end so that the part of the coil near the inductor. The length of wire in the magnetic field is $\ell$. It is equal to the circumference of the coil $(2 \cdot \pi \cdot a)$ times the number of turns (n). That is, $\ell=2 \cdot \pi \cdot a \cdot n)$.

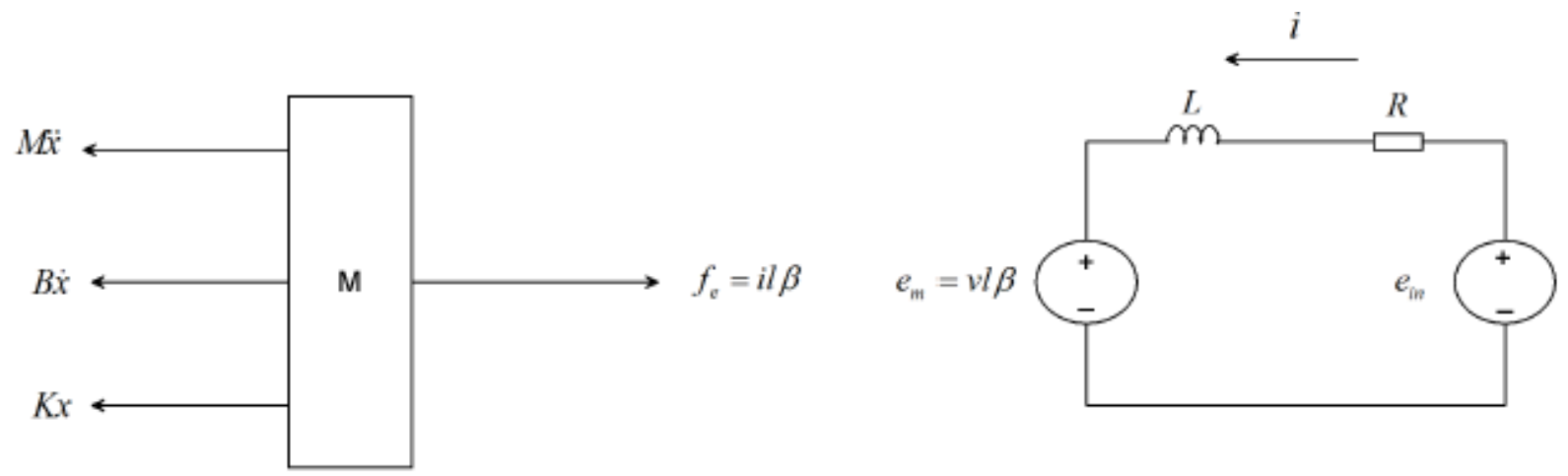

Figure 2 Electrical \& mechanical modelling diagram 


$$
\begin{gathered}
M \ddot{x}+B \dot{x}+K x=f_{e}=i l \beta=i 2 \pi a n \beta=i \alpha \\
e_{i n}-i R-L \frac{d i}{d t}=e_{m}=v l \beta=v 2 \pi a n \beta=v \alpha=\dot{x} \alpha
\end{gathered}
$$

By eliminating the current from Equation (1\&2) and taking a Laplace transform of the two equations became

$$
\begin{gathered}
M s^{2} X(s)+B s X(s)+K X(s)=\alpha I(s) \\
E_{\text {in }}(s)-R I(s)-R I(s)-\operatorname{LsI}(s)=\alpha s X(s)
\end{gathered}
$$

Solve for current from Equation (3) yields

$$
I(s)=\frac{M s^{2} X(s)+B s X(s)+K X(s)}{\alpha}
$$

and substitute into Equation (4) yields

$$
\left(s^{3} L M+s^{2}(R M+L B)+s\left(R B+L K+\alpha^{2}\right)+R K\right) X(s)=\alpha E_{i n}(s)
$$

So the transfer function of the loud speaker becomes

$$
\frac{X(s)}{E_{\text {in }}(s)}=\frac{\alpha}{\left(s^{3} L M+s^{2}(R M+L B)+s\left(R B+L K+\alpha^{2}\right)+R K\right)}
$$

The loudspeaker parameters are shown in Table 1 below.

Table 1 Loudspeaker parameters

\begin{tabular}{|c|c|c|c|}
\hline No & Parameters & Symbol & Value \\
\hline 1 & Mass of the cone & $M$ & $0.05 \mathrm{Kg}$ \\
\hline 2 & Inductance & $L$ & $0.2 \mathrm{H}$ \\
\hline 3 & Resistance & $R$ & $10.25 \Omega$ \\
\hline 4 & Spring stiffness & $K$ & $0.025 \mathrm{~N} / \mathrm{m}$ \\
\hline 5 & Damping coefficient & $B$ & $0.25 \mathrm{N.s} / \mathrm{m}$ \\
\hline 6 & Electromagnetic force constant & $\alpha$ & $0.01 \mathrm{~N} / \mathrm{A}$ \\
\hline
\end{tabular}

The transfer function numerically becomes

$$
\frac{X(s)}{E_{\text {in }}(s)}=\frac{1}{s^{3}+56.25 s^{2}+256.76 s+25.625}
$$

\section{The Proposed Controllers Design}

\subsection{Static Output Feedback Controller Design}


Consider a LTI system:

$$
\delta x(t)=A x(t)+B u(t) \quad y(t)=C x(t)
$$

Where

$$
\delta x(t)=\dot{x}(t)
$$

$x(t) \in R^{n}, u(t) \in R^{m}, y(t) \in R^{1}$ are state, control and output vectors, respectively; $\mathrm{A}, \mathrm{B}, \mathrm{C}$ are constant matrices.

The controlled feedback law is considered in the form

$$
u(t)=N y(t)=N C x(t)=K x(t)
$$

where $\mathrm{N}$ represents the static output feedback controller gain matrix. The system closed-loop form becomes

$$
\delta x(t)=A_{c} x(t)
$$

where

$$
A_{c}=A+B N C
$$

The block diagram of the loudspeaker with static output feedback controller gain matrix is shown in Figure 3 below.

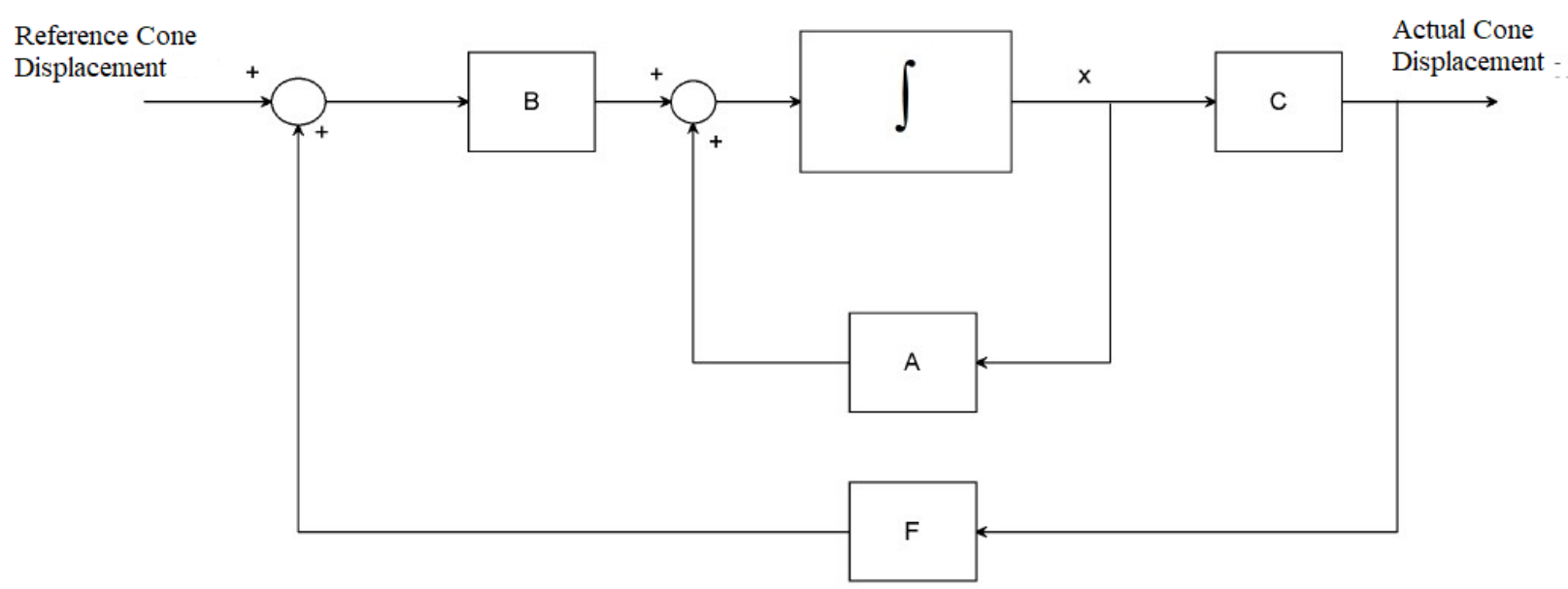

Figure 3 Block diagram of the loudspeaker system with static output feedback controller gain matrix

With a performance index

$$
J_{c}=\int_{0}^{\infty}\left[x(t)^{T} Q x(t)+u(t)^{T} R u(t)+\delta x(t)^{T} S \delta x(t)\right] d t
$$


The static output feedback controller gain matrix becomes

$$
N=[2.04]
$$

Then the feedback control law is becoming

$$
\begin{gathered}
u(t)=[3.32] y(t)=\left(\begin{array}{cccc}
1 & 0 & 0 & 0
\end{array}\right) x(t) \\
K=\left(\begin{array}{llll}
2.04 & 0 & 0 & 0
\end{array}\right)
\end{gathered}
$$

\subsection{H $\infty$ Optimal Loop Shaping Control}

$\mathrm{H} \infty$ Optimal Loop Shaping Control stabilizes the $H_{\infty}$ controller $K$ for plant $G$ to shape the sigma plot with the two given functions

$$
\begin{aligned}
& \sigma(G(j \omega) K(j \omega)) \geq \frac{1}{\gamma} \sigma\left(G_{d}(j \omega)\right) \text { for all } \omega>\omega_{0} \\
& \sigma(G(j \omega) K(j \omega)) \geq \gamma \sigma\left(G_{d}(j \omega)\right) \text { for all } \omega>\omega_{0}
\end{aligned}
$$

The system stability min-phase shaping pre-filter $W$, the shaped system $G_{s}=G W$, the controller for the shaped plant $K_{s}=W K$, with a frequency range $\left\{\omega_{\min }, \omega_{\max }\right\}$ must be achieved. The block diagram of the loudspeaker system with $\mathrm{H} \infty$ Optimal Loop Shaping Controller is shown in Figure 4 below.

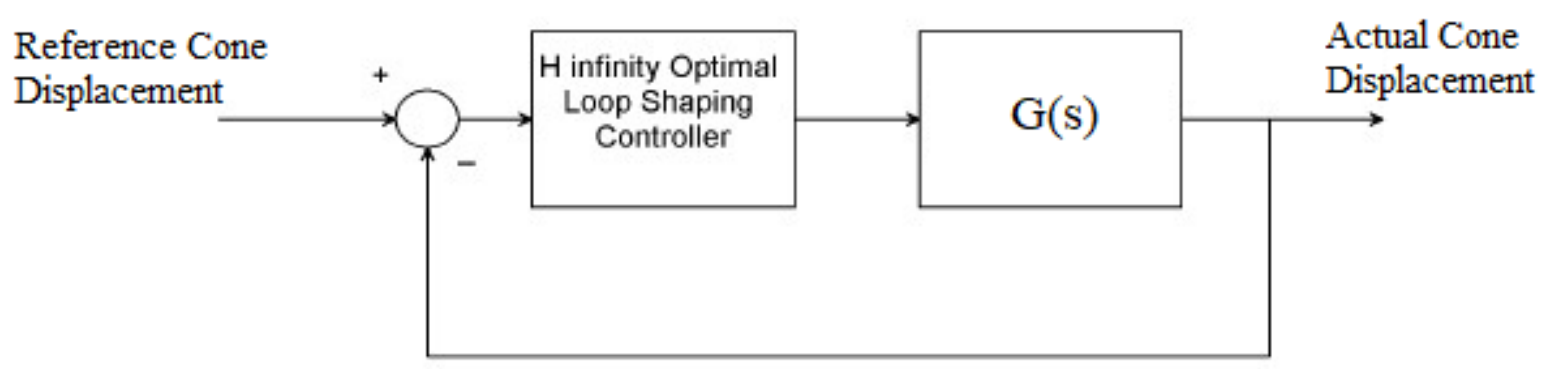

Figure 4 Block diagram of the loudspeaker system with $\mathrm{H}$ œ Optimal Loop Shaping Controller The plant desired loop shaping function is

$$
G_{d}=\frac{2}{s+13}
$$

And the $\mathrm{H} \infty$ Optimal Loop Shaping Controller becomes

$$
K_{l s}(s)=\frac{2.0324 s^{3}+4.476 s^{2}+10.4439 s+31.4015}{s^{4}+8.2751 s^{3}+10.3820 s^{2}+22.8418 s+16.1955}
$$

\subsection{Method to Determine Noise Acoustic Wave}

The cone displacement is responsible for pushing the air molecules back and forth in order to create sound wave. Tracking a reference cone displacement and observing the actual and reference cone displacement must be the same signals in order to say the loudspeaker doesn't generate a noise signal.

\section{Result and Discussion}




\subsection{Comparison of the Loudspeaker with Static Output Feedback and $H \infty$ Optimal Loop Shaping Controllers for Noise signal Control using Sine Wave Signal}

The simulation result of the loudspeaker with static output feedback and $\mathrm{H} \infty$ optimal loop shaping controllers for noise reduction improvement using sine wave signal is shown in Figure 5 below.

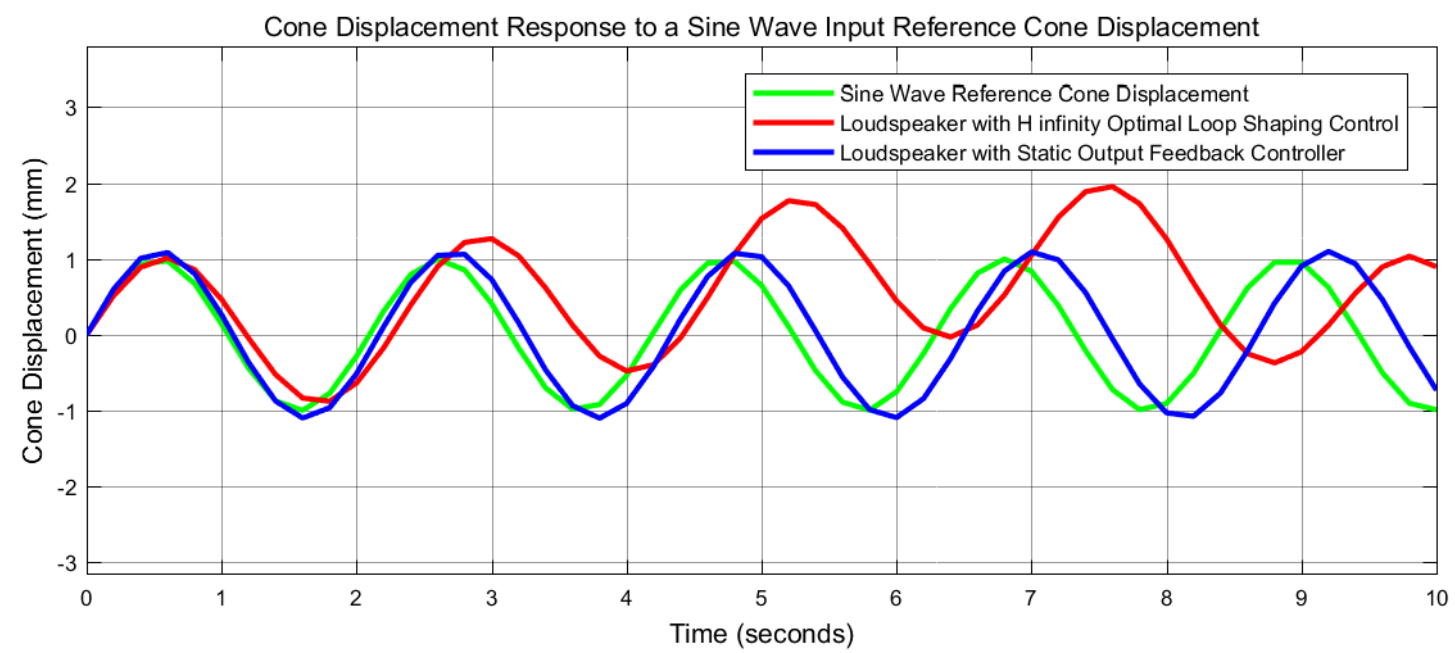

Figure 5 Sine wave response

The simulation result shows that the loudspeaker with static output feedback controller almost track the reference cone displacement with $0.1 \%$ noise in the amplitude and $0.15 \%$ in lagging the signal while the loudspeaker with $\mathrm{H}$ $\infty$ optimal loop shaping controller has a $50 \%$ in the amplitude and $14 \%$ in lagging the signal.

\subsection{Comparison of the Loudspeaker with Static Output Feedback and $H \infty$ Optimal Loop Shaping Controllers for Noise signal Control using Random Signal}

The simulation result of the loudspeaker with static output feedback and $\mathrm{H} \infty$ optimal loop shaping controllers for noise reduction improvement using random signal is shown in Figure 6 below.

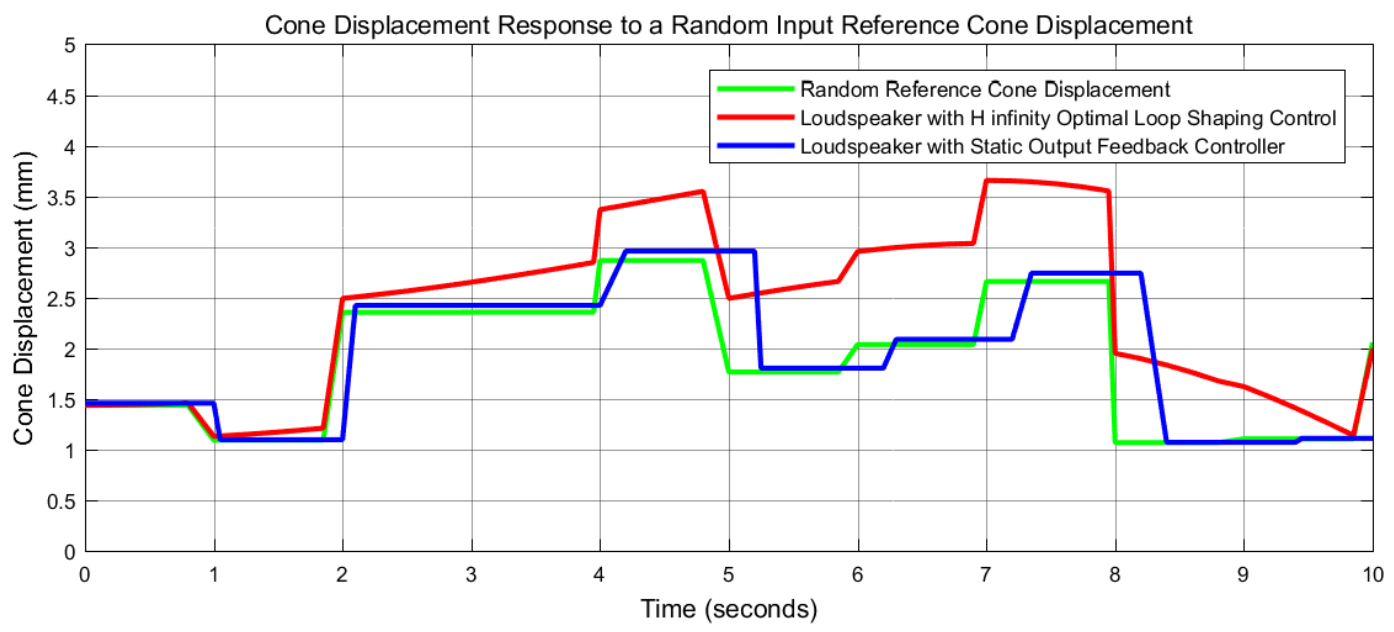

Figure 6 Random signal response 
The simulation result shows that the loudspeaker with static output feedback controller almost track the reference cone displacement with $0.12 \%$ noise in the amplitude and $0.3 \%$ in lagging the signal while the loudspeaker with $\mathrm{H}$ o optimal loop shaping controller has a $60 \%$ in the amplitude and $10 \%$ in lagging the signal.

\section{Conclusion}

The noise disturbance control of a loudspeaker has been done using static output feedback and $\mathrm{H}$ $\infty$ optimal loop shaping controllers. The noise has been analyzed by tracking a reference and actual cone displacement signals. The comparison results of the sine and random wave signals proved the effectiveness of the loudspeaker with static output feedback controller in minimizing the noise disturbance from the loudspeaker.

\section{Reference}

[1].L. H. Tong et al. "Highly Directional Acoustic Waves Generated by a Horned Parametric Acoustic Array Loudspeaker” J. Vib. Acoust, Vol. 141, Issue. 1, 7 pages, 2019.

[2]. Theodoros T. et al. "Active Acoustic Resonators with Reconfigurable Resonance Frequency, Absorption and Bandwidth”, Phys. Rev. Applied, Vol. 12, 054064, 2019.

[3]. Cai, Yinshan et al. "A Narrowband Active Noise Control Algorithm Considering the Harmonic Distortion of the Loudspeaker", International Symposium on Applied Electromagnetics and Mechanics- ISEM, 2019.

[4]. Yue Hu et al. "Effects of the Cone and Edge on the Acoustic Characteristics of a Cone Loudspeaker" Advances in Acoustics and Viberation, Vol. 2, pp. 1-12, 2017.

[5]. Marco Alunno et al. "Directional Landscapes: using Parametric Loudspeakers for Sound Reproduction in Art” Journal of New Music Research, Vol. 46, Issue 2, 2017.

[6]. Shi C. et al. "Volterra Model of the Parametric Array Loudspeaker Operating at Ultrasonic Frequiencies" J. Acoustic Soc. Am, Vol. 140, Issue 5, pp. 3643-3650, 2016.

[7].Kyle Devine "A Mysterious Music in the Air: Cultural Origins of the Loudspeaker" Popular Music History, Vol. 8, No. 1, 2014.

[8]. Vecky C. et al. "Unidirectional Sound Signage for Speech Frequency Range using Multiple Loudspeaker Reproduction System”, Open Journal of Acoustics, Vol. 3, Issue 4, pp. 120 126, 2013. 